\title{
Associative effects of information framing
}

\author{
IRWIN P. LEVIN \\ University of Iowa, Iowa City, Iowa
}

\begin{abstract}
Previous research has demonstrated that the way in which information is presented or framed affects the evaluation and choice of objects such as consumer purchases. In the present study, more favorable associations to a purchase of ground beef were produced when the beef was described in terms of "percent lean" rather than "percent fat." It is suggested that such associations to stimulus labels serve as mediators of the effects of information frame on judgment and decision making.
\end{abstract}

The study of how information frame affects judgments and decisions has both theoretical and applied significance. Kahneman and Tversky (1979; Tversky \& Kahneman, 1981) conducted pioneer work showing that the choice between two alternative courses of action depends upon whether the alternatives are compared in terms of relative gains or relative losses. The former frame generally leads to risk aversion, whereas the latter generally leads to risk taking. Because this phenomenon could not be explained by traditional notions of utility maximization, new theoretical development was needed to explain it. Prospect theory (Kahneman \& Tversky, 1979) explains the framing effect in terms of differences in the form of the value function for gains and for losses.

Neale and Bazerman (1985) applied this theory to negotiator behavior. They found support for the prediction that negatively framed negotiators are less concessionary, resolve fewer contracts, and have less successful contracts than positively framed negotiators.

Recent research in my laboratory extends this line of investigation to directly examine how judgments of single stimuli are affected by information frame. Levin, Johnson, Russo, and Deldin (1985) showed that evaluations of gambles, consumer purchases, and student performance were more favorable when a key attribute was framed in positive terms than when the same attribute was framed in negative terms. Levin et al., (1986) showed that the effects of information frame on judgments of individual choice options were predictive of choices between options. Using Anderson's (1981) and Mellers and Birnbaum's (1982) suggestions for separating the component processes of information integration, Levin et al. (1986) identified the locus of the framing effect on decisions as the evaluation of stimuli, rather than as the transformation of internal evaluations into overt responses.

The present study was designed to achieve increased understanding of the role of information frame on the evaluation of individual stimuli. The specific hypothesis under investigation was that framing a stimulus in posi-

Requests for reprints should be addressed to the author at the Department of Psychology, University of Iowa, Iowa City, IA 52242. tive terms is more likely to lead to favorable associations than framing the same stimulus in negative terms. The task required subjects to indicate their associations to a purchase of meat that was alternatively described as $75 \%$ lean or as $25 \%$ fat. The use of the label "lean" was expected to produce more favorable associations than the use of the label "fat."

\section{METHOD}

\section{Subjects}

The subjects were 102 students in introductory psychology classes at the University of Iowa who were completing part of a research participation requirement. The experimental material of present interest was printed on a single page of a larger booklet containing material for several short, unrelated experimental procedures.

\section{Procedure}

Different forms of the material were included in two different experimental conditions. Subjects in the positive framing condition $(n=55)$ were instructed to consider a purchase of ground beef that was described as $75 \%$ lean. Subjects in the negative framing condition $(n=47)$ were to consider a purchase of ground beef that was described as $25 \%$ fat. The remainder of the instructions were as follows:

In this brief survey we want to know what associations or thoughts come to mind when making consumer purchases. We will present you with pairs of possible associates. In each pair we want you to indicate by filling in one of the squares which item in the pair you are most apt to associate with a purchase of $75 \%$ lean (25\% fat) ground beef and the extent to which you associate the purchase with that item rather than the other item in the pair.

Printed below these instructions were four horizontal arrays of seven squares each, labeled as follows:

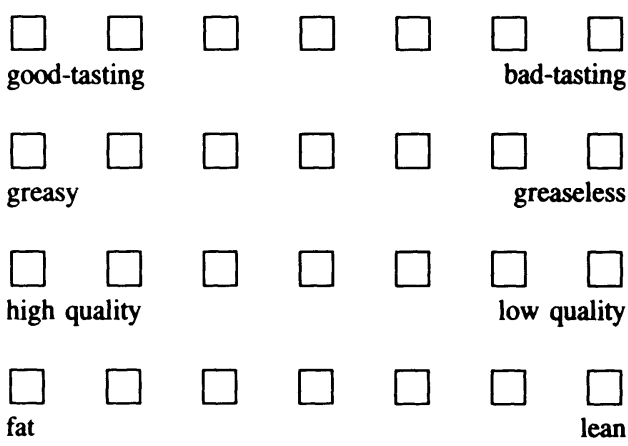


Responses were scored by converting to a scale of -3 to +3 , with positive values representing the positive item in the pair (good-tasting, greaseless, high quality, lean) and negative values representing the negative item. Zero represents the midpoint of the scale.

\section{RESULTS}

For each pair, responses were significantly higher (more favorable) in the positive framing condition than in the negative framing condition ( $p<.01$ in each case). The largest difference was for the pair lean-fat, for which the means were +1.15 and -1.17 for the positive and negative conditions, respectively $[t(100)=6.95]$. For the pair high quality-low quality, the means were +1.33 and $-0.34[t(100)=5.17]$, for the pair greaseless-greasy, the means were +0.49 and $-1.04[t(100)=4.77]$; and for the pair good-tasting-bad-tasting, the means were +1.69 and $+0.43[t(100)=3.95]$. These results are summarized in Figure 1.

\section{DISCUSSION}

The prediction that the "percent lean" label would produce more favorable associations than the "percent fat" label was supported. Ground beef that was said to be $75 \%$ lean was rated as leaner, of higher quality, less greasy, and better tasting than beef that was said to be $25 \%$ fat.

Now that we have shown that information frame affects both the associations to a stimulus and the overall evaluation of that stimulus (Levin et al., 1986; Levin et al., 1985), it is of interest to consider which effect mediates the other. It is possible in the present case that the implicit formation of an overall impression of the meat purchase served as a mediator of responses to the specific rating scales; however, the task did not call for an overall evaluation of the meat purchase. Furthermore,

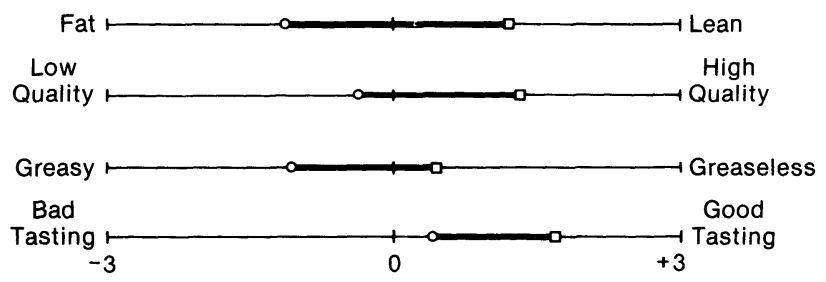

Figure 1. Mean response on each rating scale in positive condition (squares) and negative condition (circles). both the absolute ratings and the differences in ratings between framing conditions varied across scaling dimensions. As can be seen in Figure 1, the greatest difference between conditions and the greatest degree of symmetry about the neutral point occurred along the lean-fat dimension. This is not surprising, given the compatibility between the labeling of the stimulus object and the rating scale. By contrast, even though the difference between conditions was statistically significant, both the "percent lean" and the "percent fat" labels produced positive evaluations on the taste dimension. These results show that each response dimension was responded to separately, rather than being influenced solely by a generalized halo effect produced by the stimulus label. ${ }^{1}$

A parsimonious interpretation of the results obtained in the present study and its predecessors is that the stimulus label elicits associations which, in turn, affect the evaluation of the stimulus object. Framing the description of the stimulus object in positive terms leads to more favorable associations than does framing the object in negative terms.

\section{REFERENCES}

ANDERSON, N. H. (1981). Foundations of information integration theory. New York: Academic Press.

Kahneman, D., \& Tversky, A. (1979). Prospect theory: An analysis of decision under risk. Econometrica, 4, 362-377.

Levin, I. P., Johnson, R. D., Deldin, P. J., Carstens, L. M., CresSEY, L. J., \& DAvis, C. R. (1986). Framing effects in decisions with completely and incompletely described alternatives. Organizational Behavior \& Human Decision Processes, 38, 48-64.

LeVin, I. P., Johnson, R. D., Russo, C. P., \& Deldin, P. J. (1985). Framing effects in judgment tasks with varying amounts of information. Organizational Behavior \& Human Decision Processes, 37, 362-377.

Mellers, B. A., \& Birnbaum, M. H. (1982). Loci of contextual effects in judgment. Journal of Experimental Psychology: Human Perception \& Performance, 8, 582-601.

Neale, M. A., \& Bazerman, M. H. (1985). The effects of framing and negotiation overconfidence on bargaining behaviors and outcomes. Academy of Management Journal, 28, 34-49.

TVersky, A., \& KaHneman, D. (1981). The framing of decisions and the psychology of choice. Science, 211, 453-458.

\section{NOTE}

1. The intercorrelation between dimensions ranged from .44 for leanfat versus good-tasting-bad-tasting to .82 for lean-fat versus greaselessgreasy in the $75 \%$ lean group, and from .61 for lean-fat versus goodtasting-bad-tasting to .80 for lean-fat versus high quality-low quality in the $25 \%$ fat group.

(Manuscript received for publication October 14, 1986.) 